\title{
Intent to Compound 506E Drug
}

National Cancer Institute

\section{Source}

National Cancer Institute. Intent to Compound 506E Drug. NCI Thesaurus. Code C112087.

A compounder intends to produce a drug classified as 506E. 